\title{
Connective Tissue Growth Factor-(CTGF, CCN2) - A Marker, Mediator and Therapeutic Target for Renal Fibrosis
}

\author{
Mysore K. Phanish S.K. Winn M.E.C. Dockrell \\ SW Thames Institute for Renal Research, St. Helier Hospital, London, UK
}

\section{Key Words}

Connective tissue growth factor CCN2

\begin{abstract}
Connective tissue growth factor (CTGF, CCN2) is a key mediator of tissue fibrosis. CCN2 plays an important role in the development of glomerular and tubulointerstitial fibrosis in progressive kidney diseases. In this review, we discuss the biology of CCN2 with a focus on the regulation of CCN2 gene, cellular mechanisms of profibrotic CCN2 effects and the current in vivo and in vitro evidence for the role of CCN2 in the development of renal fibrosis. We also discuss the therapeutic potential of targeting CCN2 for the treatment of renal fibrosis.

Copyright $\odot 2009$ S. Karger AG, Basel
\end{abstract}

Morphologically, progressive kidney diseases are characterised by matrix deposition within the glomerulus and interstitium, loss of functioning nephrons and a variable degree of inflammatory cell infiltrate in the interstitium. The connective tissue growth factor (CTGF) $\mathrm{CCN} 2$ is an important mediator and marker of tissue fi- brosis. In this review, we discuss the biology of CCN2, the regulation of the $\mathrm{CCN} 2$ gene and the current evidence for its role in tissue fibrosis, with a focus on renal fibrosis.

CCN2 is a member of the CCN family of matricellular proteins. Matricellular proteins are contextual modulators of cell function, expressed at higher levels during development and in response to injury, made up of several domains that have distinct functions, bind to multiple receptors, other growth factors and proteases modulating their activity and mediate cross-talk between the extracellular matrix (ECM) and cells [1]. Examples of matricellular proteins include thrombospondins 1 and 2 , secreted proteins acidic in nature rich in cysteine (SPARCs), osteopontin and the CCN family of proteins. NameD after 3 prototypical members, cysteine-rich protein 61 (Cyr61; CCN1), connective tissue growth factor (CTGF; CCN2) and nephroblastoma overexpressed protein (Nov; CCN3), the CCN family comprises 6 secreted proteins grouped together on the basis of a similar predicted modular secondary structure. Human CCN2 was initially described in 1991 as a secreted protein in the conditioned media of cultured human vascular endothelial cells [2]. CCN2 is a cysteine-rich, heparin-bind-

\section{KARGER}

Fax +41613061234 E-Mail karger@karger.ch www.karger.com (c) 2009 S. Karger AG, Basel

$1660-2129 / 10 / 1143-0083 \$ 26.00 / 0$

Accessible online at:

www.karger.com/nee
Mysore K. Phanish

SW Thames Institute for Renal Research

St. Helier Hospital, Wrythe Lane, Carshalton

London, Surrey SM5 1AA (UK)

Tel. +44 2082962 935, Fax +44 2086448 257, E-Mail mysore.phanish@esth.nhs.uk 


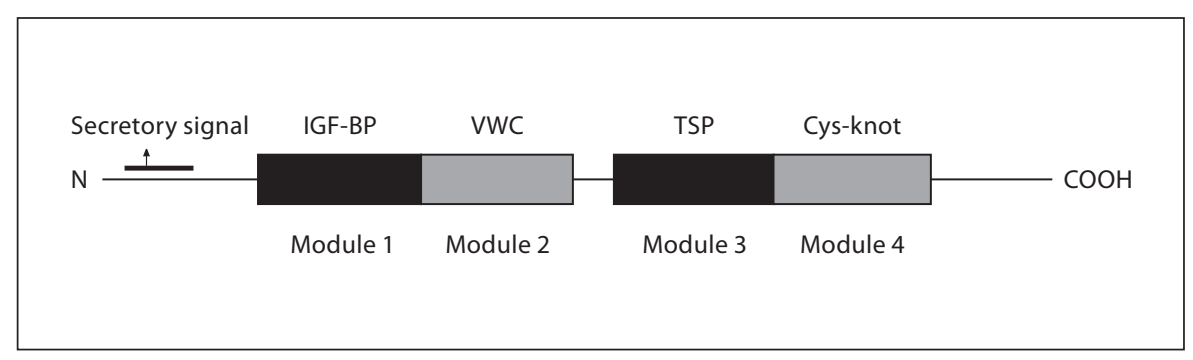

ing protein containing 349 amino acids with an apparent molecular weight of $36-38 \mathrm{kDa}$. The main post-translational processing of $\mathrm{CCN} 2$ involves glycosylation, giving rise to either 36 or $38 \mathrm{kDa}$ molecules that appear as a doublet band on Western immunoblotting. The secretion of CCN2 into the extracellular space depends on an $\mathrm{N}$-terminal 37 amino acid signal sequence. CCN2 has a modular architecture comprising of 4 modules, an insulin-like growth factor-binding domain (Module 1), a Von Willebrand factor (VWF) type C repeat domain (Module 2), a thrombospondin typel repeat domain (Module 3) and a C-terminal cysteine knot (Cys-knot) (Module 4) (fig. 1) (reviewed in [3]). Between modules 2 and 3 is the 'hinge region', which is susceptible to protease cleavage. In biological fluids, $\mathrm{CCN} 2$ can be found in various forms - full length molecule, fragments including $\mathrm{N}$-terminal and $\mathrm{C}$-terminal halves cleaved in the 'hinge region' as well as the individual 10-12 kDa C-terminal heparin-binding domain (Module 4) [4]. These variations produce a subfamily of secreted proteins with distinct functions.

CCN proteins stimulate mitosis, adhesion, apoptosis, ECM, and migration of multiple cell types [5]. They also modify the activity of other molecules such as transforming growth factor (TGF)- $\beta_{1}$, vascular endothelial growth factor (VEGF), bone morphogenetic protein (BMP) 4 and BMP7 [5]. CCN2 plays an important role in normal development and differentiation. CCN2 is important for cell proliferation and matrix remodelling during chondrogenesis and is a key regulator in coupling extracellular remodelling to angiogenesis. Mice homozygous for deletion of the CCN2 gene die soon after birth with defective ossification of bones and defective chondrogenesis [6]. An important physiological function of CCN2 in an adult is to participate in wound healing [7].

Among the $\mathrm{CCN}$ proteins, only $\mathrm{CCN} 2$ has been shown to have pro-fibrotic properties. In addition, CCN2 also has pro-angiogenic properties, which it shares with other members of the CCN family [3]. Gary Grotendorst in 1997 demonstrated the pro-fibrotic role of CCN2 acting downstream of TGF- $\beta_{1}$ [8]. CCN2 was shown to be an immediate-early gene potently induced by TGF- $\beta_{1}$. Subsequently, other pro-fibrotic stimuli such as angiotensin II, endothelin, glucose, thrombin, advanced glycation end products, stretch and oxidative stress have been shown to induce CCN2 [5]. CCN2 is overexpressed in diabetic nephropathy, chronic allograft nephropathy, scleroderma, lung fibrosis and hepatic fibrosis $[3,5,9]$. $\mathrm{CCN} 2$ is a downstream mediator of at least some of the profibrotic effects of TGF- $\beta_{1}$ and also has its own profibrotic effects. An increasing amount of literature on $\mathrm{CCN} 2$ in the last few years has demonstrated that CCN2 is both a mediator and marker of tissue fibrosis. Therefore, there is a real potential for CCN2 to become a clinically useful tool for noninvasive monitoring of tissue fibrosis and a therapeutic target for the treatment of tissue fibrosis.

\section{The Regulation of CCN2 Expression}

Of the CCN family, the only member whose gene regulation has been characterized in detail is CCN2. Current evidence suggests that $\mathrm{CCN} 2$ is primarily regulated at the level of transcription. Synthesis of CCN2 protein and mRNA is stimulated by specific growth factors, such as endothelin 1 and TGF- $\beta_{1}$, in addition to environmental changes such as hypoxia and biomechanical stimuli such as stretch in a cell type-specific manner. TGF- $\beta_{1}$-mediated induction of CCN2 mRNA in fibroblasts occurs within 30 min of TGF- $\beta_{1}$ treatment, without involving de novo protein synthesis [8]. In fibroblasts, the TGF- $\beta_{1}$ and $-\beta_{2}$ induction of CCN2 is dependent on Smad3, PKC and Ras/MEK/ERK signalling. Leask et al. [10] demonstrated that a $5^{\prime}$-GAGGAATG-3' sequence located between -126 and -77 of the CCN2 promoter that binds to TEF/TEAD 
family of transcription factors is necessary for the fibroblast-specific induction of CCN2 by TGF- $\beta_{2}$. This report identified a central role for PKC, Smad3, Ras/MEK/ERK and a consensus TEF/TEAD binding motif in TGF- $\beta_{2}$ induction of CCN2 [10]. Interestingly, in contrast to normal skin fibroblasts, fibroblasts obtained from scleroderma skin lesions constitutively overexpress CCN2 [11]. While TGF- $\beta_{1}$ and $-\beta_{2}$ induction of CCN2 in fibroblasts are critically dependent on Smad signalling, the constitutive overexpression of CCN2 in scleroderma fibroblasts was independent of Smad signalling [12]. The TGF- $\beta$ response element (TßRE/BCE-1), first identified by Grotendorst et al. [13] in 1996, has been shown subsequently to be mainly important in the regulation of basal expression of CCN2 and consequently was renamed BCE-1 (basal control element-1) [12]. A sequence similar to the consensus SMAD site (GTCTAGAC) is located in the region of the CCN2 promoter immediately upstream of the BCE-1.

This sequence is located between -173 and -166 and is shown underlined:

5'-CGAGCTTTTCAGACGGAGGAATGCTGAGTGTCA-3. This sequence in the CCN2 promoter has been shown to bind Smad3 and Smad4 [12]. Mutation of this site resulted in marked inhibition of TGF- $\beta_{1}$-induced $\mathrm{CCN} 2$ gene promoter activity but had no effect on basal promoter activity in normal and scleroderma fibroblasts [12]. Mutation of BCE-1, which is located immediately downstream of the Smad binding site, in CCN2 promoter markedly reduces constitutive expression of CCN2 gene promoter both in normal fibroblasts and in fibroblasts obtained from scleroderma skin lesions. However, in rat mesangial cells, a Smad binding site in the CCN2 promoter was required for both basal and TGF- $\beta_{1}$-induced CCN2 gene promoter activity [14].

With regards to the epithelial cells, skin keratinocytes and MvLu lung epithelial cells do not express CCN2 [12], while epithelial cells of mesenchymal origin, such as type 2 alveolar cells, expressed CCN2 [15]. Wang et al. [9] in 2001 were the first group to demonstrate expression of CCN2 in proximal tubular epithelial cells (PTECs). These authors demonstrated increased secretion CCN2 in response to TGF- $\beta_{1}$ in mouse primary proximal tubule cells. We demonstrated expression of CCN2 protein, mRNA and gene promoter activity in basal conditions in human PTECs with significant increases in response to TGF- $\beta_{1}$ treatment [16]. The other renal epithelial cells that express CCN2 are glomerular visceral epithelial cells (podocytes) [37]. It is worth considering renal development at this stage. Most of the nephron, except for the distal segments of distal convoluted tubules and collecting ducts, is derived from the metanephric mesenchyme by a process of mesenchymal to epithelial transdifferentiation during embryonic life [17]. The expression of CCN2 by tubule cells and podocytes but not by other epithelial cells could be attributed to its embryonic origin from the mesenchyme and to the fact that these cells retain 'plasticity' and ability to dedifferentiate and trans-differentiate. We have previously demonstrated that PTECs express CCN2 before de-differentiation sets in, as TGF- $\beta_{1}$ induction of CCN2 occurs before E-cadherin loss which is thought to be an early step in the induction of epithelial-mesenchymal transition [16]. Therefore, PTECs can express CCN2 without losing epithelial phenotype. In PTECs, TGF- $\beta_{1}$ induction of CCN2 protein and gene promoter activity is dependent on Smad signalling, as TGF- $\beta_{1}$ induction of CCN2 gene promoter activity and protein were markedly inhibited by Smad7 over-expression. By using RNA interference to achieve selective and specific knock down of Smad2, Smad3 and Smad4 we further demonstrated that the induction of CCN2 by TGF- $\beta_{1}$ is $\operatorname{Smad} 3$ and Smad4 dependent but Smad2 independent [18]. Similar to the fibroblasts but in contrast to the mesangial cells, the basal expression of CCN2 gene promoter activity and protein in PTECs is independent of Smad signalling [16]. The Ras/MEK/ERK1/2 signalling pathway is also required for the induction of CCN2 by TGF$\beta_{1}$ in human PTECs while the induction occurs independent of PI3-kinase-Akt signalling. However, intact Smad signalling is essential for the induction of CCN2 by TGF- $\beta_{1}$ in human PTECs, as in Smad7 over-expressing human kidney cells (HKC clone 8 , an SV-40 transformed human PTEC cell line) TGF- $\beta_{1}$ induction of CCN2 was inhibited in the presence of intact early activation of ERK1/2 by TGF- $\beta_{1}$ [16]. It is possible that transcription factors activated by MEK/ERK1/2 signalling cascade (yet to be identified) form synergistic complexes with Smad3 and Smad4 for the optimal induction of $\mathrm{CCN} 2$ gene in tubule cells. Among the Ras isoforms that are expressed in HKCs, $\mathrm{N}$ Ras but not ki Ras or Ha Ras were required for the induction of CCN2 by TGF- $\beta_{1}$ (unpublished data, manuscript accepted for publication in Nephron Exp Nephrol).

Polymorphisms in the CCN2 gene could provide an explanation for variable susceptibility to renal disease and its progression in diabetic patients. Single nucleotide polymorphisms have been identified in CCN2 gene promoter. However, so far no correlation between these polymorphisms and renal disease has been demonstrated. 


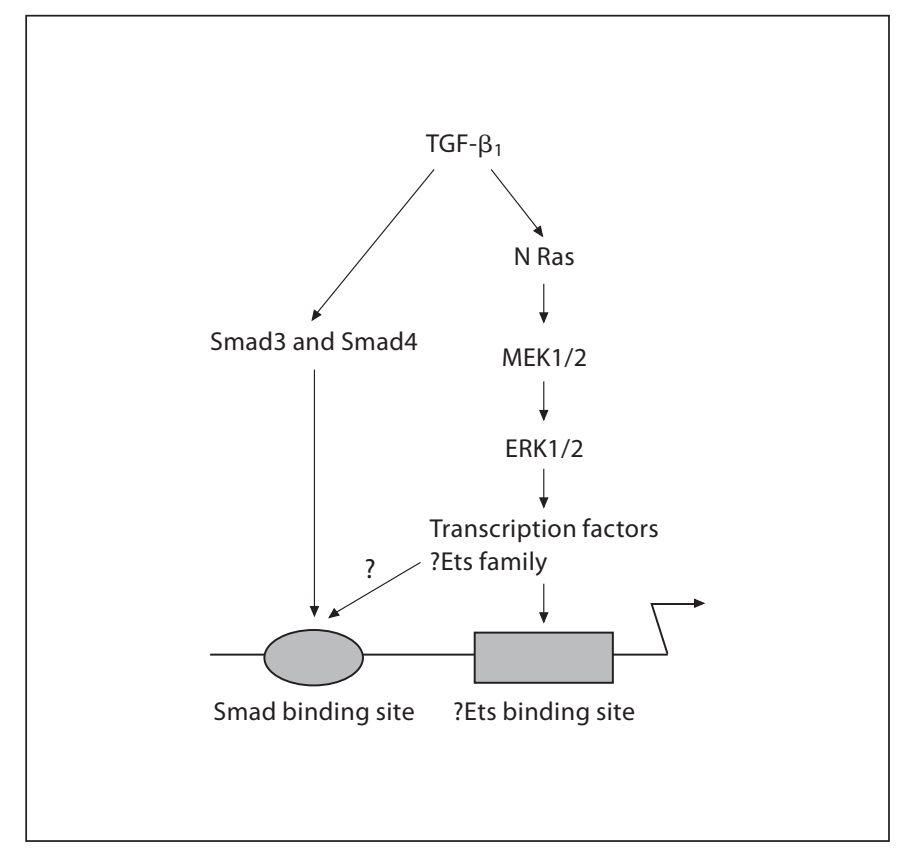

Fig. 2. Summary of signalling proteins involved in the regulation of CCN2 gene in human PTECs.

With respect to scleroderma, a recent elegant study conducted in 1,000 subjects by Abraham and co-workers [19] demonstrated modulation of CCN2 gene transcription by a polymorphism (G-945C) in its promoter. The $-945 \mathrm{G}$ allele was shown to be significantly associated with susceptibility to systemic sclerosis. A similar large scale study needs to be done in patients with diabetic and nondiabetic renal disease.

Signalling pathways involved in the regulation of CCN2 production in response to TGF- $\beta_{1}$ in human PTECs are shown in figure 2.

\section{The Role of CCN2 in Tissue Fibrosis - Evidence from in vitro and in vivo Studies}

CCN2 is thought to be an important player in the pathogenesis of chronic fibrotic disorders. CCN2 has been shown to be involved in fibrosis of various organ systems including liver, lung, skin and kidney [3, 9]. Elevated levels of CCN2 are seen in serum of patients with systemic sclerosis and the levels correlate with severity and extent of cutaneous fibrosis as well as presence or absence of lung fibrosis [20]. Scleroderma fibroblasts constitutively over express CCN2 and this is thought to play an important role in the maintenance of scleroderma phenotype independent of TGF- $\beta_{1}$-Smad signalling [12]. In one of the early in vivo studies investigating the expression of CCN2 in human renal fibrosis, increased expression of CCN2 mRNA was seen in glomeruli and in the interstitium adjacent to the areas of interstitial fibrosis in biopsy specimen from various renal disorders such as diabetic nephropathy, IgA nephropathy and focal segmental glomerulosclerosis [21]. Wang et al. [9] investigated in vivo expression of CCN2 in renal cortex of rats with streptozotocin-induced diabetes mellitus. In this study, increased expression of CCN2 was seen in the renal cortex of diabetic rats as compared to the controls. Proximal tubules of diabetic rats, in particular those with dilated morphology, expressed CCN2 in contrast to nondiabetic control rats in which no staining was demonstrated in the tubules.

As described in the following sections, in addition to its own profibrotic effects, CCN2 potentiates profibrotic functions of TGF- $\beta_{1}[22]$ and mediates at least some of the profibrotic TGF- $\beta_{1}$ effects, in particular proliferation of fibroblasts and secretion of ECM proteins by the fibroblasts [24]. CCN2 and TGF- $\beta$ act synergistically to promote chronic fibrosis. While TGF- $\beta$ has been shown to be sufficient to induce transient fibrosis, CCN2 is thought to be necessary for chronic persistent fibrosis. Mori et al. [23] have shown that subcutaneous injection of TGF- $\beta$ for 7 consecutive days only induces transient fibrosis, while co-injection of TGF- $\beta$ and CCN2 induce persistent fibrosis. Furthermore, CCN2 functions as a matricellular protein mediating cross-talk between ECM and cells and induces fibroblast and mesangial cell ECM secretion $[25,26]$. CCN2, through its C-terminal domain, binds to fibronectin and enhances affinity of fibronectin to fibrin and this facilitates wound healing [26]. Binding of CCN2 to fibronectin facilitates adhesion and migration of fibroblasts on fibronectin, a role that is likely to be important in wound healing, tissue repair and pathological fibrosis [26]. CCN2 increases the expression of fibronectin by mesangial cells, enhances fibronectin assembly into an insoluble matrix, and increases type I, type III and type IV collagen production by mesangial cells and fibroblasts $[25,26]$. CCN2 upregulates the expression of integrins on the cell surface, facilitating the deposition and assembly of ECM proteins $[25,26]$. Furthermore, in mesangial cells CCN2 caused the induction of plasminogen activator inhibitor-1, the rearrangement of the actin cytoskeleton and an increase in tissue inhibitor of metalloproteinase TIMP-1 with subsequent decrease in matrix degradation $[28,29]$. Tak- 
en as a whole, these experiments provide in vitro evidence for the pathogenic role of CCN2 in the development of mesangial matrix expansion and glomerular basement membrane thickening, which are characteristic features of diabetic nephropathy.

CCN2 has been shown to mediate tubulo-interstitial fibrosis in animal models such as the unilateral ureteric obstruction model and in cultured rat fibroblasts, CCN2 antisense treatment ameliorates TGF- $\beta_{1}$-induced fibronectin secretion [30, 31]. In addition, Gore-Hyer et al. [32] provided first evidence for the possible role of CCN2 in tubular epithelial mesenchymal transition (EMT). During the process of EMT, tubule epithelial cells lose their cell-to-cell junctions and epithelial phenotype, acquire alpha-smooth muscle actin (SMA) and a myofibroblast phenotype, upon disruption of the basement membrane, the tubule cells migrate to the interstitium to contribute to matrix deposition and fibrosis. It is thought that $20-30 \%$ of interstitial myofibroblasts within the scarring kidney are derived from tubule cells. TGF- $\beta_{1}$ is capable of inducing all the stages of EMT in tubule epithelial cells and there is some evidence to suggest that CCN2 mediates some of these TGF- $\beta_{1}$ effects. Inhibition of CCN2 by using antisense oligonucleotides (ASOs) ameliorates TGF- $\beta_{1}$ induction of $\alpha$-SMA in HKC cells [33]. In addition to its role in TGF- $\beta_{1}$-induced EMT, CCN2 has been shown to mediate EMT and renal fibrosis induced by advanced glycation end products, which is a further evidence for the role of CCN2 in the development of tubulo-interstitial fibrosis in diabetic nephropathy [34]. A direct evidence for the role of tubule cell-derived CCN2 in interstitial fibrogenesis was provided in a recent publication by Okada et al [35]. These authors used a co-culture system of mouse tubular epithelial cells and fibroblasts to demonstrate that a TGF- $\beta_{1}$-induced increase in type I collagen and fibronectin in the interstitial fibroblasts was both a direct and indirect effect, with the latter being mediated by CCN2 derived from proximal tubule epithelial cells. These authors, using neutralization protocols, provided firm evidence that tubular CCN2 directly and significantly contributes to TGF- $\beta_{1}$-dependent renal interstitial fibrogenesis. While most of in vitro experiments have focused on mesangial cells and fibroblasts, a study by Twigg et al. [36] demonstrated increased fibronectin production by proximal tubule epithelial cells in response to CCN2. All these in vitro experiments have demonstrated the increase in ECM protein production and deposition in response to CCN2 in mesangial cells, fibroblasts and tubule epithelial cells, suggesting its potential role in the development of glomerular and tubulo-interstitial fibrosis.

In diabetic renal disease, increased glomerular and renal cortical expression of CCN2 has been demonstrated in mouse models of type II (db/db mouse) and type 1 diabetes (streptozotocin-induced) and in humans with diabetic nephropathy $[9,37,38]$.

Both in obese type 2 diabetic mice ( $\mathrm{db} / \mathrm{db}$ mouse) and in streptozotocin-induced type 1 diabetic mice, CCN2 overexpression was predominant in visceral podocytes within the glomeruli, suggesting a potential role of CCN2 in the development of podocyte injury in diabetes [37]. Diabetes-induced glomerular basement membrane thickening is attenuated in CCN2 +/- mice in parallel with reduction in podocyte expression of CCN2 [37]. This study and the study by Mori et al. [23] have provided direct evidence for the role of CCN2 in the development of tissue fibrosis. In a recently published work, Yokoi et al. [39] established podocyte-specific CCN2transgenic mice. Twelve weeks after streptozotocin-induced diabetes, these transgenic mice showed more severe proteinuria, mesangial expansion, and a decrease in matrix metalloproteinase-2 activity compared to diabetic wild-type mice. Furthermore, diabetic transgenic mice exhibited less podocin expression compared to diabetic wild-type mice. Induction of diabetes in these CCN2-transgenic mice resulted in a further elevation of endogenous CCN2 mRNA expression and protein in the glomerular mesangium. This work has provided further in vivo evidence for the role of CCN2 in the development of podocyte injury and mesangial expansion in diabetes [39].

$\mathrm{CCN} 2$ is emerging as a promising biomarker of renal and vascular disease in diabetes and of chronic allograft nephropathy in renal transplant patients. Goldschmeding and co-workers [40] recently published their data on a prospective study conducted in type 1 diabetic patients. In this study, plasma CCN2 was higher in patients with macroalbuminuria compared to those with normoalbuminuria. In patients with nephropathy, elevated plasma $\mathrm{CCN} 2$ was an independent predictor of end-stage renal disease and correlated with the rate of decline in glomerular filtration rate. Plasma CCN2 was also an independent predictor of overall mortality [40]. In contrast, in normoalbuminuric patients, plasma CCN2 did not correlate with clinical parameters and did not predict outcome. Another study by the same group demonstrated significantly higher urinary CCN2 excretion in type 1 diabetic patients with micro- or macroalbuminuria compared to patients with normal albumin excretion and a 
positive correlation between the degree of albuminuria and CCN2 excretion [41]. Local production of CCN2 in the kidney, renal filtration of plasma CCN2, together with tubular dysfunction and/or saturation of tubular reabsorption capacity in proteinuric patients may all be involved in increased urinary CCN2 excretion. In our laboratory, we have seen an increase in $\mathrm{CCN} 2$ secretion by PTECs treated with human serum albumin in a MEK/ ERK-dependent manner (unpublished data). Proteinuria could contribute to increased urinary CCN2 levels by increasing the secretion of CCN2 by PTECs. Another recent study explored the significance of CCN2 as a determinant of renal and vascular complications among patients with type 1 diabetes. These investigators measured the circulating and urinary levels of whole molecule of CCN2 and the N-terminal fragment in 1,050 patients with type 1 diabetes. They found a positive and independent association between CCN2-N-terminal fragment levels and albumin excretion rate. Patients with macroalbuminuria had higher levels of CCN2-N-terminal fragment than diabetic subjects with or without microalbuminuria. Furthermore, this study demonstrated an independent and significant association of CCN2-N-terminal fragment with the common and internal carotid intimamedia thickness. These authors concluded that plasma CCN2 is a risk marker of diabetic renal and vascular disease [42].

All the in vivo and in vitro evidence described above provide strong evidence for the profibrotic role played by CCN2 in the development of progressive kidney diseases, in particular diabetic nephropathy. Moreover, these studies provide evidence for the role of CCN2 as a marker of renal disease and fibrosis and a predictor of the development of end-stage renal disease and mortality.

\section{Modulation of Signalling and Activity of Other Growth Factors by CCN2}

CCN2 exerts many of its biological effects by modulating the effects of other growth factors such as TGF$\beta$, BMP-7 and VEGF. Experiments using recombinant CCN2 and neutralising antibodies to CCN2 have suggested that CCN2 mediates at least some of the effects of TGF- $\beta_{1}$ on fibroblast proliferation, adhesion and ECM production [8]. The study by Qi et al. [36] suggested that CCN2 is dependent on TGF- $\beta_{1}$ activity for its profibrotic effects and they also demonstrated that TGF- $\beta_{1}$ and $\mathrm{CCN} 2$ have additive effects in the production of fibro- nectin by human PTECs and fibroblasts. In this study, CCN2 induction of fibronectin in human PTECs and fibroblasts was inhibited in the presence of either TGF$\beta_{1}$ neutralising antibody or TGF- $\beta_{1}$ type 2 receptor neutralising antibody [36]. Abreu et al. [22] demonstrated direct binding of CCN2 to BMP4 and TGF- $\beta$ through its VWF type $C$ domain. This binding resulted in inhibition of BMP signalling and enhancement of TGF- $\beta$ signalling [22]. More recently, Wahab et al. [44] demonstrated upregulation of the transcription factor TGF- $\beta$-inducible early gene TIEG by CCN2, which in turn resulted in a reduction in cellular Smad 7 levels, thereby augmenting TGF- $\beta_{1}$ signalling. A recent study investigating the effects of CCN2 on signalling by the anti-fibrotic protein BMP7 demonstrated antagonism of BMP7 signalling by CCN2 in the diabetic kidney. This antagonism contributed to the reduction in MMP activity, increase in glomerular basement membrane thickening and albuminuria, which are features of diabetic nephropathy [43]. Furthermore, binding of CCN2 to the matrix protein fibronectin promotes fibroblast adhesive signalling and migration. CCN2 directly binds fibronectin and the fibronectin receptor integrins alpha4 betal and alpha5 and syndecan $4[25,26]$. Loss of endogenous CCN2 results in impaired spreading of fibroblasts on a fibronectin matrix and delayed alpha-smooth muscle actin fiber formation suggesting an important role of CCN2 in potentiating fibroblast adhesion and migration on fibronectin matrix, an important event in tissue development, wound healing and fibrosis [26].

These studies highlight the complexity of CCN2 biology as, in addition to its own effects via binding to multiple receptors, it modulates cell behaviour by functionally relevant interaction with other growth factors and extracellular matrix.

\section{CCN2 Effects on Cell Receptors and Signalling Pathways}

CCN2 exerts its cellular effects by multiple mechanisms. CCN2 binds to integrins, heparan sulfate proteoglycans (HSPGs) and a multi ligand low-density lipoprotein receptor (LRP) $[45,46]$. It was postulated that CCN2 binds to the cell surface HSPGs and subsequently acts through other ligands and receptors such as TGF- $\beta$ and integrins in a cell type-specific and context-dependent manner. For example, Gao and Brigstock [45] demonstrated that activated rat hepatic stellate cells were capable of adhesion to all $3 \mathrm{CCN}$ proteins via the binding of 


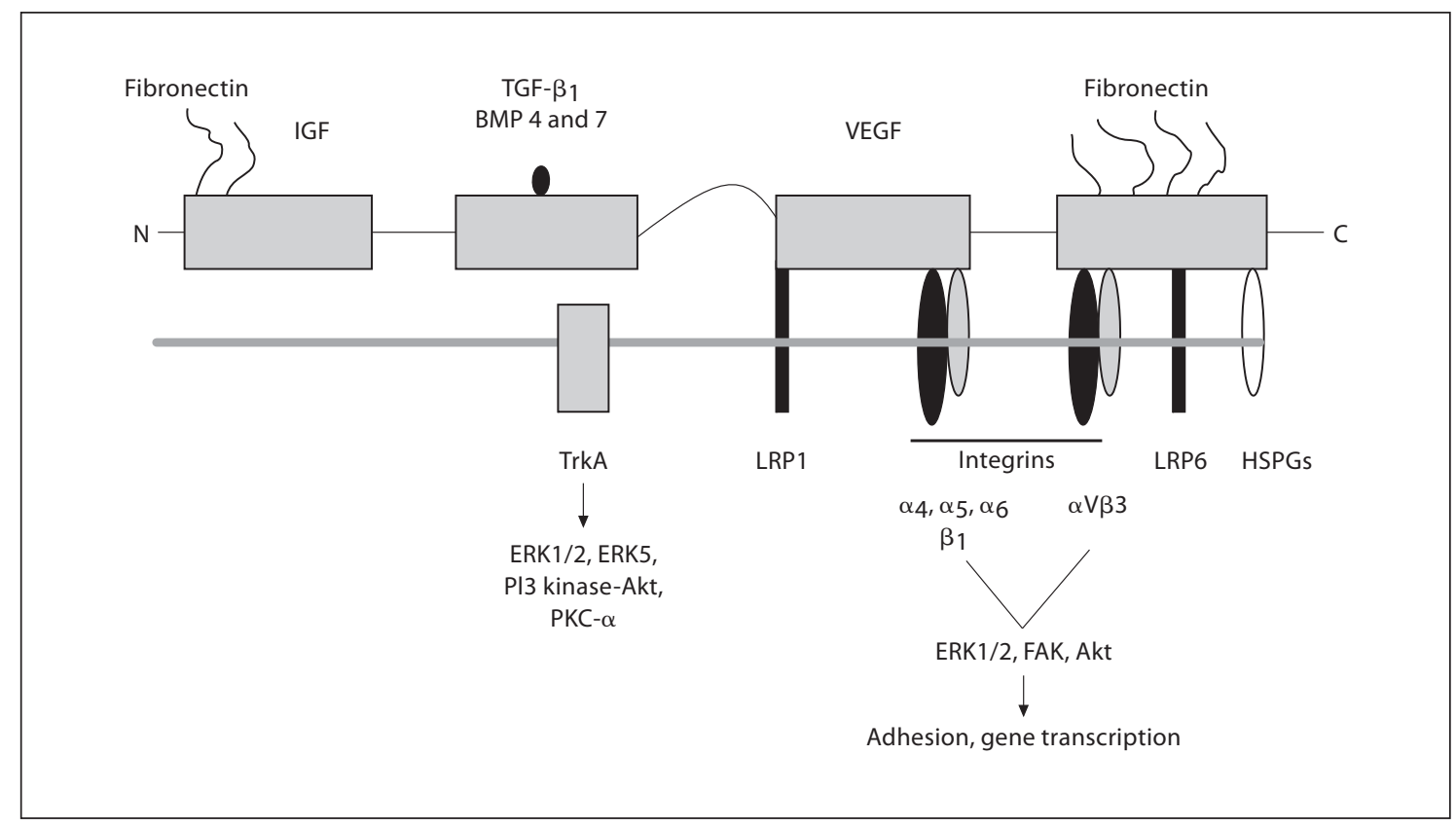

Fig. 3. Summary of binding of CCN2 to various growth factors and receptors. The domain that interacts with TrkA receptor is unknown.

module 4 to integrin alpha(v)beta(3), a process that was dependent on interactions between module 4 and cell surface HSPGs. The integrins bound by CCN2 include the integrins mediating angiogenesis and matrix attachment, such as alpha(v)beta(3), $\alpha_{5} \beta_{1}$ and $\alpha_{6} \beta_{1}[25,45]$. CCN1 and CCN2 interact with HSPGs, including syndecan 4 and perlecan, through a heparin-binding domain in module 4 [45]. CCN2 also binds to the LRP-1 [46]. These authors demonstrated that, in addition to integrins and proteoglycans, CCN2-dependent adhesion can also involve LRP-1. In the same year, it was demonstrated that a CCN2 fragment consisting of module 4 alone was bioactive, bound strongly to heparin, and promoted dosedependent adhesion of fibroblasts, myofibroblasts, endothelial cells, and epithelial cells.

All the above-mentioned studies have demonstrated that integrins and HSPGs are essential for the adhesive and mitogenic function of CCN proteins and are functional receptors for this family. In addition to these functionally relevant CCN2 receptors, recently, CCN2 has been shown to bind to and activate the nerve growth factor (NGF) tyrosine kinase receptor (TrkA) in mesangial cells in vitro [47]. Acting via this receptor, it was shown to activate several signalling pathways such as ERK1/2, ERK5, PI3 kinase and PKC- $\alpha$ in mesangial cells. How- ever, the functional significance of this interaction remains unknown. Bonofiglio et al. [48] using human renal biopsy specimen demonstrated the expression of NGF and TrkA in tubular and glomerular cells and of P75 ${ }^{\mathrm{NTR}}$, a TrkA co-receptor, in the interstitial and mesangial cells. The role of these receptors and the binding of CCN2 to these receptors in the development of renal fibrosis remain to be investigated.

Therefore, multiple biological activities can be elicited through the interactions of discrete 'functional' domains of the CCN family members and different cell surface receptors. In addition, Wahab et al. [44] reported nuclear translocation of labelled $\mathrm{CCN} 2$ protein, which raises a possibility of $\mathrm{CCN} 2$ protein functioning as a transcription factor.

The growth factors and receptors binding to $\mathrm{CCN} 2$ are shown in figure 3.

\section{Targeting CCN2 for the Treatment of Fibrosis}

Inhibition of CCN2 has been shown to be an effective antifibrotic strategy. CCN2 can be inhibited by neutralising antibodies, ASOs and small interfering RNA. FG3019, a fully human monoclonal neutralizing immuno- 
globulin G antibody against CCN2 has been developed by FibroGen for the treatment of fibrotic diseases and diabetic complications. Early results of a phase $1 \mathrm{~b}$ multicentre study testing the safety and efficacy of this antibody in diabetic patients with microalbuminuria have been published in an abstract form. In mouse models of type 1 and type 2 diabetes, treatment with ASOs targeted to $\mathrm{CCN} 2$ resulted in reduction in serum creatinine, attenuated albuminuria and reduced expression of matrix protein genes such as fibronectin and collagen in the kidney [38]. Using a chronic allograft nephropathy model of renal fibrosis, Luo et al. [49] demonstrated that delivery of siRNA targeted to CCN2 via the caudal vein significantly inhibited expression of CCN2 in rat kidneys, effectively preventing fibrosis. In the unilateral ureteric obstruction model, injection of CCN2 ASOs via the renal vein markedly attenuated the induction of CCN2 in the interstitium and reduced the deposition of fibronectin and collagen [31]. Furthermore, attenuation of interstitial fibrosis by CCN2 ASOs occurred in spite of overexpression of TGF- $\beta_{1}$ in this model, suggesting that CCN2 plays an important role in TGF- $\beta_{1}$-induced fibrogenesis. This study also highlighted the fact that it is possible to inhibit matrix deposition and fibrosis within the kidney by targeting CCN2 expression without affecting TGF- $\beta_{1}$ expression. This is of great relevance as TGF- $\beta_{1}$ has several important physiological functions and it is difficult to inhibit TGF- $\beta_{1}$ for the treatment of chronic fibrosis without having adverse effects on the health of the animal, such as induction of autoimmunity, multiorgan inflammation and development of cancers. The question remains: does CCN2 mediate any of the effects of TGF- $\beta_{1}$ on the immune system? This was in part addressed by Kunzmann et al. [50] who investigated the role of CCN2 in CD4 T lymphocyte proliferation. CCN2 alone did not have any effect on CD4 T lymphocyte proliferation and did not have any effect on the inhibition of T lymphocyte proliferation by TGF- $\beta_{1}$. Therefore, it would appear that while CCN2 has at least some profibrotic properties similar to TGF- $\beta_{1}$ and can potentiate and mediate fibrotic effects of TGF- $\beta_{1}$, it probably does not share the immunomodulatory properties of TGF- $\beta_{1}$. However, more work needs to be done to investigate the role of CCN2 in inflammation and immunity.

In summary, CCN2 is a marker and mediator of tissue fibrosis. It is an attractive therapeutic target for the treatment of fibrosis. Further studies should focus on identifying cellular mechanisms of CCN2 effects, the role of CCN2 in the effects of TGF- $\beta_{1}$ on the immune system, inflammation, regulation of cell cycle, cell proliferation and apoptosis. Further studies are required to assess the safety and efficacy of neutralising antibodies to CCN2 in patients with diabetic and nondiabetic renal disease. RNA-based therapeutic approaches continue to evolve and could be applicable to the treatment of fibrotic diseases in humans in future. Targeting CCN2 could become an effective and safe therapeutic option for the treatment of progressive renal fibrosis.

\section{References}

1 Bornstein P: Matricellular proteins: an overview. Matrix Biol 2000;19:555-556.

-2 Bradham DM, Igarashi A, Potter RL, Grotendorst GR: Connective tissue growth factor: a cysteine-rich mitogen secreted by human vascular endothelial cells is related to the SRC-induced immediate early gene product CEF-10. J Cell Biol 1991;114:1285-1294.

3 Perbal B: CCN proteins: multifunctional signalling regulators. Lancet 2004;363:6264.

\4 Brigstock DR, Steffen CL, Kim GY, Vegunta RK, Diehl JR, Harding PA: Purification and characterization of novel heparin-binding growth factors in uterine secretory fluids. Identification as heparin-regulated $\mathrm{Mr}$ 10,000 forms of connective tissue growth factor. J Biol Chem 1997;272:20275-20282.
5 Leask A, Abraham DJ: All in the CCN family: essential matricellular signaling modulators emerge from the bunker. J Cell Sci 2006;119:4803-4810.

6 Kawaki H, Kubota S, Suzuki A, Yamada T, Matsumura T, Mandai T, Yao M, Maeda T, Lyons KM, Takigawa M: Functional requirement of CCN2 for intramembranous bone formation in embryonic mice. Biochem Biophys Res Commun 2008;366:450-456.

7 Igarashi A, Okochi H, Bradham DM, Grotendorst GR: Regulation of connective tissue growth factor gene expression in human skin fibroblasts and during wound repair. Mol Biol Cell 1993;4:637-645.
-8 Grotendorst GR: Connective tissue growth factor: a mediator of TGF-beta action on fibroblasts. Cytokine Growth Factor Rev 1997; 8:171-179.

9 Wang S, Denichilo M, Brubaker C, Hirschberg R: Connective tissue growth factor in tubulointerstitial injury of diabetic nephropathy. Kidney Int 2001;60:96-105.

10 Leask A, Holmes A, Black CM, Abraham DJ: Connective tissue growth factor gene regulation. Requirements for its induction by transforming growth factor-beta 2 in fibroblasts. J Biol Chem 2003;278:13008-13015.

- 11 Holmes A, Abraham DJ, Chen Y, Denton C, Shi-wen X, Black CM, Leask A: Constitutive connective tissue growth factor expression in scleroderma fibroblasts is dependent on Sp1. J Biol Chem 2003;278:41728-41733. 
$\checkmark 12$ Holmes A, Abraham DJ, Sa S, Shiwen X, Black CM, Leask A: CTGF and SMADs, maintenance of scleroderma phenotype is independent of SMAD signaling. J Biol Chem 2001;276:10594-10601.

-13 Grotendorst GR, Okochi H, Hayashi N: A novel transforming growth factor beta response element controls the expression of the connective tissue growth factor gene. Cell Growth Differ 1996;7:469-480.

14 Chen Y, Blom IE, Sa S, Goldschmeding R, Abraham DJ, Leask A: CTGF expression in mesangial cells: involvement of SMADs, MAP kinase, and PKC. Kidney Int 2002;62: 1149-1159.

-15 Pan LH, Yamauchi K, Uzuki M, Nakanishi $\mathrm{T}$, Takigawa $\mathrm{M}$, Inoue $\mathrm{H}$, Sawai T: Type II alveolar epithelial cells and interstitial fibroblasts express connective tissue growth factor in IPF. Eur Respir J 2001;17:12201227.

-16 Phanish MK, Wahab NA, Hendry BM, Dockrell ME: TGF-beta1-Induced connective tissue growth factor (CCN2) expression in human renal proximal tubule epithelial cells requires Ras/MEK/ERK and Smad signalling. Nephron Exp Nephrol 2005; 100:e156e165.

17 Davies JA: Mesenchyme to epithelium transition during development of the mammalian kidney tubule. Acta Anat (Basel) 1996; 156:187-201.

18 Phanish MK, Wahab NA, Colville-Nash P, Hendry BM, Dockrell ME: The differential role of Smad2 and Smad3 in regulation of pro-fibrotic TGFbetal responses in human proximal tubule epithelial cells. Biochem J 2006;393:601-607.

19 Fonseca C, Lindahl GE, Ponticos M, Sestini P, Renzoni EA, Holmes AM, Spagnolo P, Pantelidis P, Leoni P, McHugh N, Stock CJ, Shi-Wen X, Denton CP, Black CM, Welsh KI, du Bois RM, Abraham DJ: A polymorphism in CTGF promoter region associated with systemic sclerosis. N Engl J Med 2007;357: 1210-1220.

20 Sato S, Nagaoka T, Hasegawa M, Tamatani T, Nakanishi T, Takigawa M, Takehara K: Serum levels of connective tissue growth factor are elevated in patients with systemic sclerosis: association with extent of skin sclerosis and severity of pulmonary fibrosis. J Rheumatol 2000;27:149-154.

-21 Ito Y, Aten J, Bende RJ, Oemar BS, Rabelink TJ, Weening JJ, Goldschmeding R: Expression of connective tissue growth factor in human renal fibrosis. Kidney Int 1998; 53:853861.

-22 Abreu JG, Ketpura NI, Reversade B, De Robertis EM: Connective-tissue growth factor (CTGF) modulates cell signalling by BMP and TGF-beta. Nat Cell Biol 2002;4: 599-604.
23 Mori T, Kawara S, Shinozaki M, Hayashi N, Kakinuma T, Igarashi A, Takigawa $\mathrm{M}, \mathrm{Na}$ kanishi T, Takehara K: Role and interaction of connective tissue growth factor with transforming growth factor-beta in persistent fibrosis: a mouse fibrosis model. J Cell Physiol 1999;181:153-159.

24 Frazier K, Williams S, Kothapalli D, Klapper $\mathrm{H}$, Grotendorst GR: Stimulation of fibroblast cell growth, matrix production, and granulation tissue formation by connective tissue growth factor. J Invest Dermatol 1996;107: 404-411.

25 Weston BS, Wahab NA, Mason RM: CTGF mediates TGF-beta-induced fibronectin matrix deposition by upregulating active alpha5betal integrin in human mesangial cells. J Am Soc Nephrol 2003; 14:601-610.

26 Chen Y, Abraham DJ, Shi-Wen X, Pearson JD, Black CM, Lyons KM, Leask A: CCN2 (connective tissue growth factor) promotes fibroblast adhesion to fibronectin. Mol Biol Cell 2004; 15:5635-5646.

27 Lam S, van der Geest RN, Verhagen NA, van Nieuwenhoven FA, Blom IE, Aten J, Goldschmeding R, Daha MR, van Kooten C: Connective tissue growth factor and igf-I are produced by human renal fibroblasts and cooperate in the induction of collagen production by high glucose. Diabetes 2003;52:29752983.

28 Crean JK, Furlong F, Finlay D, Mitchell D, Murphy M, Conway B, Brady HR, Godson $\mathrm{C}$, Martin F: Connective tissue growth factor [CTGF]/CCN2 stimulates mesangial cell migration through integrated dissolution of focal adhesion complexes and activation of cell polarization. FASEB J 2004;18:15411543.

29 McLennan SV, Wang XY, Moreno V, Yue DK, Twigg SM: Connective tissue growth factor mediates high glucose effects on matrix degradation through tissue inhibitor of matrix metalloproteinase type 1: implications for diabetic nephropathy. Endocrinology 2004; 145:5646-5655.

30 Yokoi H, Mukoyama M, Sugawara A, Mori K, Nagae T, Makino H, Suganami T, Yahata K, Fujinaga Y, Tanaka I, Nakao K: Role of connective tissue growth factor in fibronectin expression and tubulointerstitial fibrosis. Am J Physiol Renal Physiol 2002;282:F933F942.

31 Yokoi H, Mukoyama M, Nagae T, Mori K, Suganami T, Sawai K, Yoshioka T, Koshikawa M, Nishida T, Takigawa M, Sugawara A, Nakao K: Reduction in connective tissue growth factor by antisense treatment ameliorates renal tubulointerstitial fibrosis. J Am Soc Nephrol 2004;15:1430-1440.

32 Gore-Hyer E, Shegogue D, Markiewicz M, Lo S, Hazen-Martin D, Greene EL, Grotendorst G, Trojanowska M: TGF-beta and CTGF have overlapping and distinct fibrogenic effects on human renal cells. Am J Physiol Renal Physiol 2002;283:F707F716.
33 Zhang C, Meng X, Zhu Z, Liu J, Deng A: Connective tissue growth factor regulates the key events in tubular epithelial to myofibroblast transition in vitro. Cell Biol Int 2004;28:863-873

-34 Zhou G, Li C, Cai L: Advanced glycation end-products induce connective tissue growth factor-mediated renal fibrosis predominantly through transforming growth factor beta-independent pathway. Am J Pathol 2004; 165:2033-2043.

35 Okada H, Kikuta T, Kobayashi T, Inoue T, Kanno Y, Takigawa M, Sugaya T, Kopp JB, Suzuki H: Connective tissue growth factor expressed in tubular epithelium plays a pivotal role in renal fibrogenesis. J Am Soc Nephrol 2005; 16:133-143.

-36 Qi W, Twigg S, Chen X, Polhill TS, Poronnik P, Gilbert RE, Pollock CA: Integrated actions of transforming growth factor-betal and connective tissue growth factor in renal fibrosis. Am J Physiol Renal Physiol 2005;288: F800-F809.

-37 Roestenberg P, van Nieuwenhoven FA, Joles JA, Trischberger C, Martens PP, Oliver N, Aten J, Hoppener JW, Goldschmeding R: Temporal expression profile and distribution pattern indicate a role of connective tissue growth factor (CTGF/CCN-2) in diabetic nephropathy in mice. Am J Physiol Renal Physiol 2006;290:F1344-F1354.

38 Guha M, Xu ZG, Tung D, Lanting L, Natarajan R: Specific down-regulation of connective tissue growth factor attenuates progression of nephropathy in mouse models of type 1 and type 2 diabetes. FASEB J 2007;21:33553368

39 Yokoi H, Mukoyama M, Mori K, Kasahara M, Suganami T, Sawai K, Yoshioka T, Saito Y, Ogawa Y, Kuwabara T, Sugawara A, Nakao $\mathrm{K}$ : Overexpression of connective tissue growth factor in podocytes worsens diabetic nephropathy in mice. Kidney Int 2008;73: 446-455

$\checkmark 40$ Nguyen TQ, Tarnow L, Jorsal A, Oliver N, Roestenberg P, Ito Y, Parving HH, Rossing P, van Nieuwenhoven FA, Goldschmeding R: Plasma connective tissue growth factor is an independent predictor of end-stage renal disease and mortality in type 1 diabetic nephropathy. Diabetes Care 2008;31:11771182.

41 Nguyen TQ, Tarnow L, Andersen S, Hovind $\mathrm{P}$, Parving HH, Goldschmeding R, van Nieuwenhoven FA: Urinary connective tissue growth factor excretion correlates with clinical markers of renal disease in a large population of type 1 diabetic patients with diabetic nephropathy. Diabetes Care 2006;29: 83-88.

42 Jaffa AA, Usinger WR, McHenry MB, Jaffa MA, Lipstiz SR, Lackland D, Lopes-Virella M, Luttrell LM, Wilson PW: Connective tissue growth factor and susceptibility to renal and vascular disease risk in type 1 diabetes. J Clin Endocrinol Metab 2008;93:18931900. 
-43 Nguyen TQ, Roestenberg P, van Nieuwenhoven FA, Bovenschen N, Li Z, Xu L, Oliver $\mathrm{N}$, Aten J, Joles JA, Vial C, Brandan E, Lyons KM, Goldschmeding R: CTGF inhibits BMP-7 signaling in diabetic nephropathy. J Am Soc Nephrol 2008;19:2098-2107.

44 Wahab NA, Weston BS, Mason RM: Modulation of the TGFbeta/Smad signaling pathway in mesangial cells by CTGF/CCN2. Exp Cell Res 2005;307:305-314.

45 Gao R, Brigstock DR: Connective tissue growth factor (CCN2) induces adhesion of rat activated hepatic stellate cells by binding of its C-terminal domain to integrin alpha(v)beta(3) and heparan sulfate proteoglycan. J Biol Chem 2004;279:8848-8855.
46 Gao R, Brigstock DR: Low density lipoprotein receptor-related protein (LRP) is a heparin-dependent adhesion receptor for connective tissue growth factor (CTGF) in rat activated hepatic stellate cells. Hepatol Res 2003;27:214-220.

47 Wahab NA, Weston BS, Mason RM: Connective tissue growth factor CCN2 interacts with and activates the tyrosine kinase receptor TrkA. J Am Soc Nephrol 2005;16:340351.

48 Bonofiglio R, Antonucci MT, Papalia T, Romeo F, Capocasale G, Caroleo MC, Di Fausto V, Aloe L: Nerve growth factor (NGF) and NGF-receptor expression in diseased human kidneys. J Nephrol 2007;20:186-195.
49 Luo GH, Lu YP, Song J, Yang L, Shi YJ, Li YP: Inhibition of connective tissue growth factor by small interfering RNA prevents renal fibrosis in rats undergoing chronic allograft nephropathy. Transplant Proc 2008;40:23652369.

50 Kunzmann S, Seher A, Kramer BW, Schenk R, Schutze N, Jakob F, Sebald W, Speer CP: Connective tissue growth factor does not affect transforming growth factor-beta 1-induced Smad3 phosphorylation and T lymphocyte proliferation inhibition. Int Arch Allergy Immunol 2008; 147:152-160. 